\title{
Definición y desafíos de una hermenéutica bíblica latinoamericana
}

\author{
Armand Puig \\ Ateneu Universitari Sant Pacià, Barcelona \\ arpt@tinet.org
}

Resumen: El presente artículo busca recoger y estructurar teológicamente las exposiciones y discusiones realizadas durante del cuarto encuentro del grupo regional de Latinoamérica y el Caribe de la Studiorum Novi Testamenti Societas (SNTS), que estuvo centrado en la siguiente pregunta ¿Existe una hermenéutica bíblica propia de Latinoamérica? El presente trabajo se hace eco de manera personal de los desafíos planteados en el encuentro, que giraron en torno a las relaciones entre exégesis científica y hermenéutica contextual. Primero se desarrolla la necesidad de la exégesis científica como condición para la interpretación del texto bíblico. Luego se pasa a describir algunos elementos centrales de la hermenéutica latinoamericana, basados en tres palabras clave: pueblo, pobres y cultura. Los diversos momentos de la lectura de la Escritura no deben ser comprendidos como sucesivos, sino articulados en una circularidad incesante.

Palabras clave: exégesis bíblica, hermenéutica latinoamericana, Nuevo Testamento

Abstract: This paper seeks to summarize and offer a theological structure to the contributions submitted to the forth meeting of the Latin American and Caribean section of Studiorum Novi Testamenti Societas (SNTS). The seminar studied the following question: Is there a Latin American biblical hermeneutics? The main discussion was about the relationship between scientific exegesis and contextual hermeneutics. The first part of the paper explains the need of scientific exegesis as previous condition for the interpretation of the biblical text. The second, describes some central components of the Latin American hermeneutics: people, poor and culture. Exegesis and hermeneutics are not successive but permanently circular intellectual exercises.

Keywords: biblical exegesis, Latin American hermeneutics, New Testament. 


\section{INTRODUCCIÓN}

El presente artículo ofrece un balance teológico del cuarto encuentro del grupo regional de Latinoamérica y el Caribe de la Studiorum Novi Testamenti Societas (SNTS) ${ }^{1}$. El encuentro se realizó en Santiago, entre el 3 y el 5 de septiembre de 2018, en la Facultad de Teología de la Pontificia Universidad Católica de Chile. La reunión contó con la participación de 25 profesores, de Argentina, Brasil, Chile, Colombia, España, Guatemala, México, Puerto Rico y Uruguay. El encuentro fue guiado por la pregunta: ¿Existe una hermenéutica bíblica propia de Latinoamérica? Se buscó avanzar en una reflexión acerca la forma de lectura de la Biblia que se ha desarrollado en América Latina, que aún no ha encontrado una formulación académica adecuada. Algunas presentaciones abordaron directamente el tema principal, mientras que otras desarrollaron temas particulares, pero con una particular atención al carácter «situado» de la interpretación bíblica.

\section{LA EXÉGESIS CONDICIÓN PARA LA HERMENÉUTICA}

El punto de partida para renovar y afianzar una hermenéutica latinoamericana es concebir adecuadamente el acto interpretativo como una conjunción entre una exégesis metodológicamente sólida y una hermenéutica contextualmente fundamentada. La dialéctica entre la búsqueda del sentido del texto y su significación actual en la vida y la historia, en el hoy del lector, debe ser mantenida y practicada con rigor. Es preciso delimitar y mantener las especificidades que existen entre métodos (los exegéticos) y lecturas (las hermenéuticas), entre el proceso de "explicar" y el de "comprender". Si no es así, el acto global de interpretación resulta confuso y puede derivar en cortacircuitos internos. En consecuencia, en sentido estricto, es impropio hablar de "exégesis canónica" o de "exégesis liberacionista": la aproximación canónica o liberacionista son hermenéuticas o lecturas del texto, efectuadas a partir de una exégesis crítica previa que analiza el texto y extrae de él los elementos principales desde los cuales llevar a término el proceso de actualización.

1 Los encuentros anteriores se realizaron en Bard College, Nueva York el año 2011; en el Seminario Mayor, Bogotá el año 2012; y en McGill University, Montreal el año 2016.

2 Cf. Pontificia Comisión Bíblica, "La interpretación de la Biblia en la Iglesia", 1993 y las hermenéuticas de Gadamer y Ricoeur. 
El acto de interpretación consta de un horizonte (la pre-comprensión) y de dos momentos substantivos (la exégesis y la hermenéutica) que deben relacionarse desde una dialéctica fecunda y una circularidad incesante. El horizonte o la pre-comprensión es la "lectura primera" o "lectura ingenua" del texto bíblico, en la cual este texto adquiere un carácter "pro-vocativo" (interpelativo) en relación a la realidad. Con el término "realidad" se quiere designar la vida concreta de las personas y los pueblos latinoamericanos, el contexto social y existencial en el que viven, la historia de la que participan. Aquí se encuentra la ubicación propia de las ciencias sociales e históricas y, sobre todo, el lugar donde se manifiesta la sensibilidad hacia los pobres y se detectan las lagunas, dolores, injusticias, heridas interiores, anhelos, visiones y sueños que surgen en el interior de las personas y los pueblos. Es en este momento cuándo la Iglesia como comunidad creyente se reconoce como tal, y se comprende a sí misma como comunidad interpretativa, como sujeto histórico y hermenéutico en la que los pobres ocupan un lugar preferencial como maestros en la fe y fuente del conocimiento de Dios. El horizonte de pre-comprensión o de "lectura primera" del texto puede llevarse adelante mediante diversos métodos - por ejemplo, el método de ver-juzgar-obrar, introducido por la Juventud Obrera Católica y practicado, entre otros, por Carlos Mesters-. En cualquier caso, el principio de la primacía del texto ("in principio erat textus", que equivale a decir "in principio erat Verbum loquens") está llamado a iluminar la realidad y la historia de América Latina, un continente donde la mayoría de la población ya es urbana y vive mayoritariamente en enormes periferias, que son el lugar donde el Evangelio puede crecer con más fuerza.

La exégesis de los textos es necesaria en la medida que sin ella no hay base sólida para la comprensión o hermenéutica y en la medida que la búsqueda del sentido del texto significa escuchar la Palabra que está contenida en las palabras de aquel. Es verdad que la revelación de Dios es más grande que la Palabra escrita, la Biblia, pero sin ésta no hay acceso a aquella. La exégesis es ante todo la búsqueda del sentido primario del texto, al cual se llega investigando la "letra" - procurando no caer en un literalismo de tipo fundamentalista que deforma la interpretación del texto bíblico. Por esta razón, en no pocas ocasiones las aproximaciones "directas" por parte de los lectores resultan suficientes. Mencionemos como ejemplo el texto donde Jesús cita los dos mandamientos más 
importantes de la Ley: "Amarás al Señor tu Dios con todo tu corazón, con toda tu alma, con todas tus fuerzas y amarás al prójimo como a ti mismo". Sin embargo, incluso en este caso cabe preguntarse, como hizo un doctor de la Ley: "¿Y quién es mi prójimo?”" Jesús no dejó esta crucial pregunta sin una respuesta: la parábola del buen samaritano ${ }^{5}$.

La exégesis crítica es necesaria para una lectura popular de la Biblia, es decir, una lectura hecha con la vida y desde la vida, que propone una comprensión actualizadora del texto bíblico. La exégesis proporciona los conocimientos necesarios para dar respuesta a las preguntas que plantean los lectores del texto bíblico y para descubrir a estos las riquezas inmensas de la Biblia. No se trata de efectuar un juego preciosista o intelectualista o bien de proponer meras hipótesis que fragmentarían el texto en pequeñas unidades. Hoy en día la pregunta exegética que se plantean quienes investigan críticamente el Nuevo Testamento, no es tanto el origen o la formación de los textos -como en los tiempos de la Formgeschichte- sino (a) el papel de la tradición y las tradiciones y su transmisión oral y escrita, (b) los contextos históricos, culturales y religiosos, y (c) los procedimientos retóricos, socio-históricos y antropológicos, que se detectan en los textos bíblicos.

Esto significa que los métodos histórico-críticos, aplicados de forma amplia y renovada, no deben ser considerados en absoluto "enemigos de la fe", siempre que el exégeta interprete el texto bíblico en el marco de la fe de la Iglesia. Esta es una condición insoslayable. Precisamente una de las grandes tareas de la exégesis bíblica, que por definición es plural, es fecundar la lectura popular de la Biblia a partir de los resultados de la investigación bíblica. No se trata de confundir la hermenéutica popular del texto bíblico con una investigación exegética, sino de aprovechar los frutos de esta investigación para dar "cuerpo" y fundamento a la lectura de la Biblia y, concretamente, del Nuevo Testamento, que debe llevar a cabo el pueblo de Dios. Los métodos exegéticos deben ser conocidos y aplicados en los círculos académicos, pero lo que debe llegar al pueblo son los resultados y no el método de análisis. Este es el gran servicio que

3 Dt 6,5 y Lv 19,18, textos que están incluidos en Mt 22,37-39.

$4 \quad$ Lc 10,29

5 Lc 10,30-37. 
debe prestar la exégesis latinoamericana a la Iglesia. Un campo importante de comprensión hermenéutica es la homilía dominical ${ }^{6}$. Esta presupone la exégesis del texto, pero no debe ser en ella misma una exégesis sino una hermenéutica del texto o textos que han sido proclamados en el transcurso de la celebración.

La hermenéutica del texto bíblico debe partir de una buena exégesis que permita actualizar el texto en el presente histórico y vital de la comunidad interpretativa. La comunidad interpretativa, la Iglesia, se apropia del texto y lo sitúa en el hoy y el aquí de la Palabra divina y revelada ${ }^{7}$. Cuando se llega hasta el significado que reviste el texto para el "nosotros" de los lectores u oyentes, entonces se produce de forma simultánea un proceso de transformación de los corazones, de manera que todos los que escuchan la Palabra -incluyendo a los pobres- son llamados a la conversión. El cambio de estructuras empieza en el corazón de cada uno. El diálogo del texto con el mundo y la historia presentes queda a veces mediatizado por una perspectiva determinada (feminista, liberacionista...), pero este diálogo debe ser siempre contextual, es decir, se debe encarnar y enraizar en la cultura. Si no hay concreción, la hermenéutica del texto queda estéril y sin fuerza. La Palabra de Dios puede quedar sin efectos cuando no se acierta a mostrar su impacto y su interpelación al ser humano y a la cultura. En efecto, la hermenéutica de la Palabra incluye la propuesta de un mundo nuevo, transformado. Este es un punto de fuerza de la hermenéutica latinoamericana. Mientras en Europa la mirada se ha puesto primordialmente sobre el texto y el autor (en la exégesis), en América Latina el lector y su contexto histórico ocupan el lugar relevante (en la hermenéutica). Es deseable para el futuro que las dos perspectivas se complementen adecuadamente.

6 Cf. Francisco, Evangelii gaudium, 146-148.

7 Cf. Francisco, Evangelii gaudium, 154. 


\section{UNA HERMENÉUTICA PROPIA DE LATINOAMÉRICA}

La hermenéutica latinoamericana debe inscribirse en una teología que responda a las particularidades que presenta el subcontinente latinoamericano, actualmente en fase de expansión demográfica hacia los Estados Unidos. Las palabras clave de esta hermenéutica son tres: pueblo, pobres, cultura. "Pueblo" designa un sujeto activo en la historia, una colectividad articulada, no una simple agregación derivada de la pertenencia a un área geopolítica del mundo. Es preferible pues, en el tema que nos ocupa, hablar de "pueblo latinoamericano" que de "pueblos latinoamericanos" e insistir en las diversas especificidades nacionales. La conciencia común debe prevalecer por encima de las fronteras para superar los retos que de hecho afectan a todos. En cualquier caso, América Latina es un subcontinente donde la palabra "pueblo" tiene un valor sustantivo, y este es un dato relevante e importante para una hermenéutica bíblica. Llega pues el momento de entrelazar alianzas, construir proyectos y compartir sueños, y no de refugiarse en las identidades bicentenarias, postcoloniales y nacionales. Aquí aparece la cuestión clave de la colaboración latinoamericana entre hispanófonos y lusófonos. Por otra parte, los biblistas latinoamericanos deben trabajar en una perspectiva amplia, de alcance mundial. Existe un peligro latente de aislamiento latinoamericano, cultural y mental, en relación al mundo anglófono que "produce" en este momento el más alto porcentaje de cultura bíblica. América Latina no debe caer en un "provincianismo" que subrayara sus peculiaridades pero que la dejaría culturalmente aislada del resto.

La segunda palabra clave es "pobres". Ya ha sido mencionado el gran cambio cultural y social que supone el paso de un mundo "rural" a uno "urbano" por lo que respecta a la ubicación física, pero también mental de las personas. La sociedad tecnológica y de la comunicación ha modificado los vectores culturales, y los cambios socioeconómicos piden abandonar un cierto "romanticismo" en relación al pasado y abrir un análisis que sea válido para hoy. Los pobres son los preferidos de Dios en toda la revelación bíblica. La primera opción por los pobres es la que hace Dios mismo y con él Jesús de Nazaret ${ }^{8}$. "Pobres" y "necesitados" son categorías

8 Cfr. Lc 4,16-30 
similares, así como las de "inferiores" y "descartados". Por lo tanto, se plantea si la actualización de la Palabra, la hermenéutica del texto bíblico, debe realizarse para los pobres o desde los pobres y con los pobres. Leer el texto desde los pobres y al lado de ellos significa leerlo desde la mirada de Dios sobre el mundo. Por esta razón los pobres no son los asistidos sino los sujetos activos de la historia humana.

La hermenéutica bíblica latinoamericana debe llevarse a cabo desde las periferias de las grandes ciudades. Las periferias son la plataforma de evangelización del continente americano, el lugar donde confluyen pobres y Palabra de Dios. Por consiguiente, serán las periferias las que impulsarán su evangelización. La ubicación teológica de la hermenéutica bíblica latinoamericana deben ser las periferias, allí donde viven los pobres y donde estos manifiestan su relación especial con la Palabra, su apertura a la misericordia, su percepción del don de Dios, su proximidad a un Dios vivo y no manipulable -y donde también se manifiesta su pecado en una sociedad violenta. La piedad popular es un campo privilegiado donde leer la realidad a la luz del Evangelio, como hace Jesús en el templo de Jerusalén a propósito de la viuda pobre que da dos monedas de las más pequeñas. El pobre es un creyente que confía plenamente en Dios, como la viuda de Mc 12,41-44.

La tercera palabra clave es "cultura". Nos encontramos ante otra perspectiva crucial, donde la hermenéutica latinoamericana debe afinar de modo particular el horizonte interpretativo (la pre-comprensión) y la comprensión final del texto, la que cierra y concluye el acto interpretativo. Cultura significa desarrollar un modo de vivir, de analizar y transformar el mundo, de reaccionar ante el bien y ante el mal, en una palabra, de promover el desarrollo humano integral y construir la civilización del amor. La piedad popular ha forjado cinco siglos de historia cristiana, con mestizajes diversos, procedentes de los componentes "autóctono" "indio" y "africano", a los cuales cabe añadir el componente "europeo" de base (hispano-luso) y otros componentes "europeos" y "mundiales" más recientes. América Latina es un continente mestizo, y esta es una característica clave en el mundo global, donde las identidades se mezclan y se funden. 
En la piedad popular latinoamericana la Virgen María es una figura muy importante de gran fuerza religiosa y cultural ${ }^{9}$. Una hermenéutica latinoamericana debe tener en cuenta este dato, ya que el texto bíblico ayuda a "explicar" la fuerza de María, la primera creyente ${ }^{10}$. A la piedad popular, que brota de un sentimiento enraizado en el alma latinoamericana -y que a menudo traspasa incluso las fronteras confesionales cristianasse añaden las creencias mágicas y providencialistas ${ }^{11}$. En este sentido una hermenéutica bíblica latinoamericana debe mantener el horizonte escatológico de la salvación en el presente, el reto del Reino de Dios anunciado por Jesús -que ya formó parte central de la teología de la liberación-. La hermenéutica bíblica puede mostrar la centralidad de la cultura de la gratuidad y la necesidad de abandonar una visión utilitarista e institucionalista de la religión, en la cual predomina una religión concebida como interés.

La hermenéutica latinoamericana debe mostrar, a partir de la Palabra de Dios, las luces y las sombras de la cultura dominante, entre las que sobresale el tema de la percepción de la dignidad de la persona humana. Nos encontramos en una encrucijada en la que el ser humano es considerado como poseedor de una "dignidad" absoluta, que no debe nunca mancillarse, pero que a menudo es tratado con una "violencia" inaudita, que lo reduce a objeto intercambiable. En las sociedades latinoamericanas coexisten el profundo "respeto" hacia el otro y un abierto "desdén" de la vida del otro. Esta dualidad también es profundamente bíblica: el texto bíblico integra vida y muerte, misericordia y opresión, amor y odio, amistad y rechazo. Por esta razón, la hermenéutica latinoamericana tiene que ser lúcida y profética, y debe abandonar los análisis de tipo "buenista" y paternalista. Es preciso superar la dificultad de plantearse las cosas como son, evitando la trampa ideológica de analizar la realidad con las lentes de los pre-juicios, es decir, tener una opinión previa que convierte en prejuicio lo que debería ser una necesaria pre-comprensión. Por esta razón la hermenéutica, como la exégesis, debe ser crítica, es decir, consciente de sí misma y de su tarea ejercida con libertad intelectual y existencial en el marco de la fe de la Iglesia y como servicio a la comunidad creyente y a toda la sociedad.

\footnotetext{
9 Como en Guadalupe, Aparecida, Luján, y otros lugares.

10 Cfr. Lc 1,45

11 Como "el destino", "la buena suerte" o "la prosperidad".
} 


\section{ConClusión}

La hermenéutica bíblica forma parte de un acto global de interpretación del texto, que debe ser riguroso y dialogante, y que debe conducir a formular los "nuevos paradigmas" de que habla el Papa Francisco en Evangelii gandium ${ }^{12}$. Solo así, desde la búsqueda de un proyecto común que integre todas las sensibilidades sociales, será posible un intercambio cultural con las corrientes liberales y laicistas, hijas de la Ilustración y de la Revolución francesa, que también contribuyeron a la fundación de las naciones latinoamericanas y están presentes en sus sociedades. No se puede olvidar que al lado de la componente "cristiana" hay una componente de tradición "laica", activa en muchas de estas naciones, con la que hay que dialogar y buscar complicidades. La cultura cristiana latinoamericana, históricamente de matriz católica, pero en la que también participa la matriz protestante, debe poder dialogar con la cultura no cristiana para efectuar una lectura de la realidad que desemboque en la transformación de esta realidad. Aquí es donde la hermenéutica católica latinoamericana, impregnada del Concilio Vaticano II, y particularmente de la constitución Dei Verbum, debe desarrollar un dato teológico esencial: el discernimiento de los signos de los tiempos. Es preciso que se encuentren en la historia concreta la Palabra y la vida, el Evangelio y la realidad, y que lo hagan en la persona de Jesús, el Cristo, Hijo de Dios y Salvador, Logos del Padre enviado al mundo. 


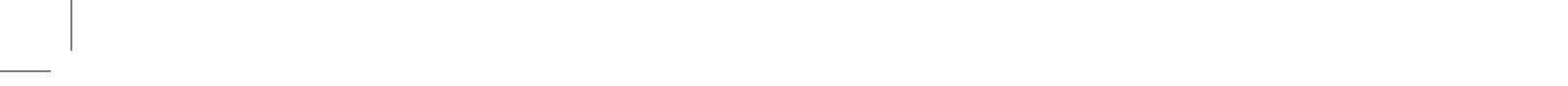

